\title{
多関節マニピュレータの冗長性分解制御
}

\author{
広 瀬 茂 男*.馬書 根*
}

\section{Redundancy Decomposition Control for Multi-Joint Manipulators}

\author{
Shigeo Hirose* and Shugen MA*
}

A new control method named "Redundancy Decomposition Control", is proposed for the resolved acceleration control of redundant manipulator. The proposed method can be summarized as follows: (1) The redundant degree of freedom of the given manipulator is decomposed into a non-redundant subset. (2) For every time interval from $t$ to $t+\Delta t$, the acceleration of the corresponding subset of degree of freedom is assumed to be controlled and the inverse dynamics as well as evaluation function are calculated using the non-redundant Jacobian inverse matrix. The calculation is parallelly performed for all the combinations of degree of freedom. (3) The optimum set of degree of freedom is selected and it is used for the control of the time interval from $t$ to $t+\Delta t$.

Comparison is made between the proposed method, and conventional methods, that is the pseudo-inverse matrix method and the null-space vector method. It is shown that the proposed method almost always realizes better motion planning than the former two methods, and has the capability to be used in real time control.

Key Words: redundancy decomposition control, decomposed inverse matrix, manipulator control, pseuđo-inverse, null-space

\section{1. まえがき}

マニピュレータにて長性を付加することは，特異姿 勢や障害物の回避など，その機能性を向上するのに効 果が大きい. 本研究は圥長な自由度を有する多関節ア 一ムを対象とし，その動力学を考慮した制御法の改善

†第 5 回日本ロボット学会学術講演会で発表 (昭 $62 \cdot 11$ )

* 東京工業大学工学部 東京都目黒区大岡山 2-12-1

* Faculty of Engineering, Tokyo Institute of Technology, Meguro-ku, Tokyo

(Received January 13, 1988)

(Revised May 17, 1988)
を試みる，冗長性分解制御亡呼ぶ制御手法を几長性を 取扱う新しい考え方として提案し, その有効性を計算 機シミュレーションにより検討する.

\section{2. 冗長マニピュレータの制御に関する 従来の研究}

本論文では動力学を考慮した制御法を検討する．動 力学を考慮したマニピュレータ制御の代表例としては 分解加速度制御 (resolved acceleration control) があ げられる1).乙れは時刻 $t$ において，アーム関節角と 角速度 (直動アームの場合は変位と速度) の計測され た值 $\boldsymbol{\theta}, \dot{\boldsymbol{\theta}}$, 先端の指令加速度 $\ddot{\boldsymbol{r}}_{d}$ を使用し, ニュート ン・オイラー法などの逆動力学演算で誘導した運動方 程式加ら

$$
\boldsymbol{\tau}=\boldsymbol{H} \ddot{\theta}_{d}+\boldsymbol{c}(\theta, \dot{\theta})+\boldsymbol{G}(\theta) \boldsymbol{g}
$$

ただし

$$
\ddot{\theta}_{d}=\boldsymbol{J}^{-1}\left(\ddot{\boldsymbol{r}}_{d}-\dot{\boldsymbol{J}} \dot{\boldsymbol{\theta}}\right)
$$

$\boldsymbol{H}:$ 慣性行列,

$\boldsymbol{J}^{-1}$ : ヤコビ逆行列,

$c(\theta, \dot{\theta})$ : 求心力とコリオリ力の影響を示すべクト ル,

$\boldsymbol{G}(\boldsymbol{\theta})$ : 重力の影響を示すべクトル,

のように関節アクチュエータへのトルク指令值 $\tau$ を生 成し，てれによってアームの制卸を行㧍うとするすの である.なお実際に使用するに当たっては，マニピュ レータ先端の指令加速度は

$$
\ddot{\boldsymbol{r}}_{d}+k_{1}\left(\dot{\boldsymbol{r}}_{d}-\dot{\boldsymbol{r}}\right)+k_{2}\left(\boldsymbol{r}_{d}-\boldsymbol{r}\right)
$$

のように, フィードバック係数 $k_{1}, k_{2}$ を乗じたマニピ ユレータ先端の速度拉よび変位の偏差を付加し, これ

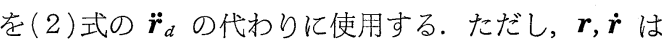
順運動学演算で誘導されたマニピュレータ先端の位置 と速度, $\boldsymbol{r}_{d}, \dot{\boldsymbol{r}}_{d}$ は先端の指令位置と速度である.

さて, マニピュレータに朵長性が存在する場合, (2)式のヤコビ逆行列 $\boldsymbol{J}^{-1}$ は一般に求まらず, $\ddot{\boldsymbol{\theta}}_{d}$ の 誘導はできない. そのためとの解の誘導過程をいかに 
取扱うかが冗長マニピュレータの場合の最大の課題と なる. 従来の㲹長マニピュレータの制御問題は，ほと んどがての点を中心に論じられている．従来の手法の うち代表的なるのは以下の二つであろう.

(1) 擬似逆行列に上るもの. 乙れは擬似逆行列 $\boldsymbol{J}^{+}$, つまり,

$$
\boldsymbol{J}^{+}=\boldsymbol{J}^{T}\left(\boldsymbol{J} \boldsymbol{J}^{T}\right)^{-1}
$$

を使用し関節加速度 $\ddot{\theta}_{d}$ を

$$
\ddot{\theta}_{d}=\boldsymbol{J}^{+}\left(\ddot{\boldsymbol{r}}_{d}-\dot{\boldsymbol{J}} \dot{\boldsymbol{\theta}}\right)
$$

之求めるあのである ${ }^{21}$.

(2) 擬似逆行列の解を関節トルクの 2 乗和最小化 条件を満足するゼロ空間べクトルで補正するもの．乙 れは関節加速度 $\ddot{\theta}_{d}$ を,

$$
\ddot{\theta}_{d}=\boldsymbol{J}^{+}\left(\ddot{\boldsymbol{r}}_{d}-\dot{\boldsymbol{J}} \dot{\boldsymbol{\theta}}\right)+\left(\boldsymbol{I}-\boldsymbol{J}^{+} \boldsymbol{J}\right) \ddot{\boldsymbol{\phi}}
$$

ただし，

$$
\ddot{\boldsymbol{\phi}}=\left[\boldsymbol{H}\left(\boldsymbol{I}-\boldsymbol{J}^{+} \boldsymbol{J}\right)\right]^{+}\left(\frac{\boldsymbol{\tau}_{\max }+\boldsymbol{\tau}_{\min }}{2}-\boldsymbol{\tau}\right)
$$

$\tau_{\max }, \tau_{\min }:$ 関節トルクの上下限ベクトル,

$\tau$ : 擬似逆行列に上る(1)の手法で誘導した関節卜 ルクベクトル，

と求めるあのである ${ }^{3)}$.

これら以外にあ, (1)慣性行列で重み付けした擬似逆 行列を使用する手法 ${ }^{2)}$ ，(2)ゼロ空間ベクトルを関節卜 ルクの上限で重み付けする手法 ${ }^{3)}$, (3)ゼ空間ベクト ルを特異值分解法でなくラグランジェの未定係数法で 誘導する手法4)，(4)ゼロ空間べクトルによってアクチ

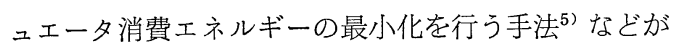
提案されている. しかし，乙れらの手法はいずれあ基 本的には擬似逆行列を使用しており, (1)以外はゼ口空 間ベクトルによる補正を行っている，そのため, 前述 の（1)，（2）によって従来の手法を代表させることは 妥当であると思われる.

さててれら従来の手法には, 二つの問題が残されて いることが報告されている3 運動を実現しようとすると，発生すべきトルクが著し く大きくなってしまうというとと、ローカルな最適化 を図っているだけであるにあかかわらず，几長自由度 が多くなると膨大な計算量が必要とされ実時間制御に は適さないということである。本論文では多くの場合 前 2 手法よりあより最適化された解が誘導でき, 演算 の高速化も可能な新しい手法を提案する.

\section{3. 几長性分解制御の提案}

制御対象とするマニピュレータは関節自由度が $n$, アーム先端の位置执よび姿勢の自由度は $m$ とし,$n>$ $m$ である冗長マニピュレータとする.とのようなマニ
ピュレータのために提案する手法は6),

（1）まずマニピュレータの関節自由度のうち, $n>m \geq p$ である非冗長な $p$ 個の関節自由度を選択 する. そして, この関節自由度 $p$ のみを時刻 $t$ から 時刻 $t+\Delta t$ に扔いて加減速し; それ以外の $(n-p)$ 自 由度は加減速せず期間 $\Delta t$ では等速運動を行うものと する.

（2）ヤコビ行列を選択された関節自由度 $p$ を用 いて,

$$
\boldsymbol{J}=\left[\boldsymbol{J}_{m \times p} \mid \boldsymbol{J}_{m \times(n-p)}\right]
$$

と小行列に分解する．そして，その逆行列を

$$
\boldsymbol{J}^{\#}=\left[\begin{array}{c}
\boldsymbol{J}_{p \times m}^{-1} \\
\cdots \cdots \cdots \\
\mathbf{0}_{(n-p) \times m} \times \cdots
\end{array}\right]
$$

のように求める. ここで, $\boldsymbol{J}_{p \times m}^{-1}$ は関節自由度数 $p$ に 対応する部分ヤコビ行列の逆行列である. (9)式の $J^{\#}$ は一般逆行列の一つである. 以後とれは「分解逆 行列 (decomposed inverse matrix)」と呼ぶととに する.

（3）（9）式の分解逆行列を使用し, 角加速度指令 值 $\ddot{\theta}_{d}$ を

$$
\ddot{\theta}_{d}=\boldsymbol{J}^{\sharp}\left(\ddot{\boldsymbol{r}}_{d}+k_{1}\left(\dot{\boldsymbol{r}}_{d}-\dot{\boldsymbol{r}}\right)+k_{2}\left(\boldsymbol{r}_{d}-\boldsymbol{r}\right)-\dot{\boldsymbol{J}} \dot{\boldsymbol{\theta}}\right)
$$

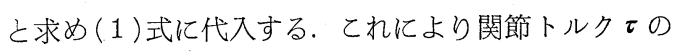
誘導を行う。とのような動力学演算を, ${ }_{n} C_{p}$ 通りの関 節自由度の組合せすべてについて行う。

（4）すべての組合せについて，トルクの 2 乗和の 最小化, アクチュエータ消費パワーの最小化, また障 害物回避特性などの評価関数の演算を行い, ${ }_{n} C_{p}$ 通り のなかで最適な組合せを選択する，そして，乙れを時 刻 $t$ から時刻 $t+\Delta t$ 亿おける制御として採用する.

以上のように，提案する手法は朵長システムを非冗 長なシステムに分解し制御しようとするあのである. そのため, 以後とれを「圥長性分解制御 (Redundancy Decomposition Control, 略して RDC)」と呼ぶとと にする.

几長性分解制御は, 分解逆行列の選択法や, 手順 (4) における評価関数の選び方によって多くの方法論 に分類できる. てのような多様な側面の検討は今後行 ってゆく. 本論文では, 圥長性分解制御之従来の方法 論との比較検討を最大の眼目としている. そのため関 節自由度 $p$ はアーム先端の位置 および姿勢の自由度 $m$ と一致しておう, 評価関数は各関節で発生する卜 ルクの 2 乗和の最小化とした一例についてのみ検討す る.

\section{4. 計算機シミュレーション}

提案する冗長性分解制御と従来の手法との比較を計 
算機シミュレーションで行った. 対象とするマニピュ レータは, 質量 $10.0 \mathrm{~kg}$, 長さ $1.0 \mathrm{~m}$ の均質な 3 リン クからなる平面マニピュレータである．関節は根元か ら先端に向汃て $1 ， 2 ， 3$ と呼ぶ. 軌道運動は，始点 と終点とで静止しておりその間三角形の加減速運動を 行い, 軌道の中点で加減速を切り換えるものとする. 軌道の長さおよび方向はシミュレーションごとに変え る. 几長性分解制御は, $m=p=2$ とし評価関数は関 節トルクの 2 乗和としている．ただし，負パワーを出 力する場合はその值はゼロにとる仮定を導入し，回生 ブレーキのない一般のアクチュエータをモデル化する ようにしている. 関節トルクが求まった後の関節の角 速度と角度の誘導は $1 \mathrm{~ms}$ ごとのテーラ一展開法によ る積分演算で行った。

結果の一例を Fig. 1 亿示す.（a ) は擬似逆行列に よる動作，（b ）はゼロ空間べクトルによる動作，（c） は提案する冗長性分解制御による動作である. Fig. 2 は上述の各例の関節角加速度 $\ddot{\theta}$ の変化を示す. 圥長 性分解制御では，動作中つぎつぎに $(1,3)(2,3)(1,3)$ (2,3) という関節の組合せを選択しているととがわか る. Fig. 3 は各関節で発生するトルクの変化を示す.
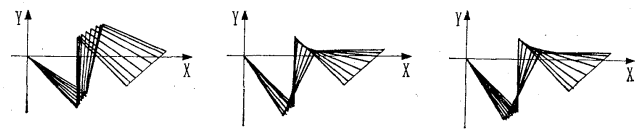

(a) Pseudo-inverse (b) Null-space matrix method b) Null-space
vector method

(c) Redundancy decomposition

Fig. 1 Comparison of the arm motion between the two conventional methods ( a ), (b) and the proposed method (c).

Motion time $t=1.77(\mathrm{~s})$ and acceleration $a=1.0\left(\mathrm{~m} / \mathrm{s}^{2}\right)$

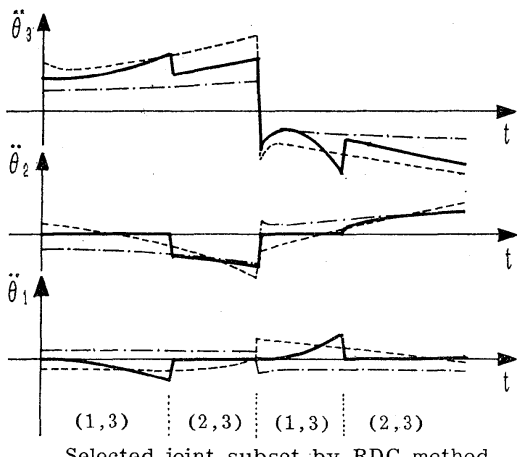

Selected joint subset by RDC method

-._ pseudo-inverse matrix method; -..-., nullspace vector method; - $\longrightarrow$ RDC method

Fig. 2 Acceleration profiles of joints 1,2,3
Fig. 4 はトルクの 2 乗和の変化を示す.（a ), ( b )の 手法とも加速度の切換え時に大きなトルクを必要とし ている. 特に擬似逆行列手法ではパルス状の大きなト

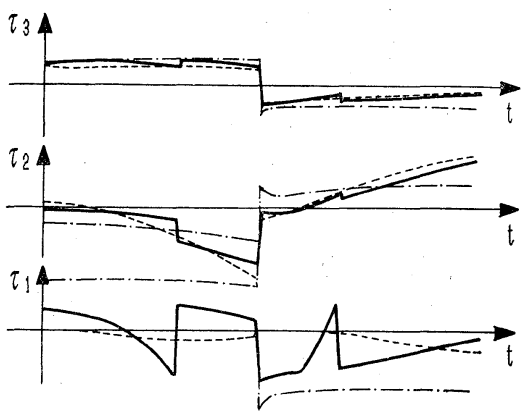

-_., pseudo-inverse matrix method; ...., nullspace vector method; - $\longrightarrow$ RDC method

Fig. 3 Torque profiles of joints 1,2, 3 coresponding to acceleration profiles of Fig. 2

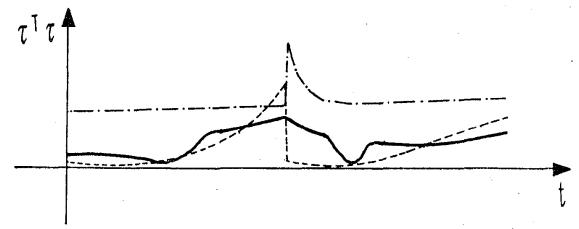

-.-, pseudo-inverse matrix method; ....., nullspace vector method; —, RDC method

Fig. 4 Profiles of squared torque for the three methods (Fig. 1 (a), (b), (c))

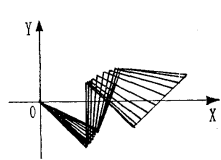

(a) Pseudo-inverse matrix method

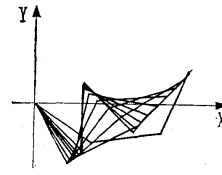

(b) Null-space vector method

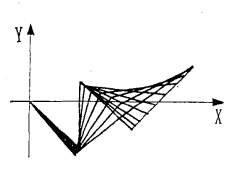

(c) Redundancy decomposition control method

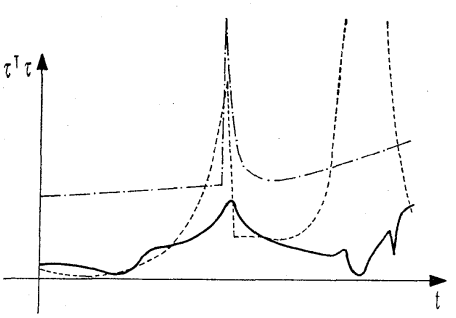

---, pseudo-inverse matrix method; -.---, null-space vector method; —

(d)

Fig. 5 The arm motion and profiles of their squared torques to track the long trajectory.

Motion time $t=2.30(\mathrm{~s})$ and acceleration $a=1.0$ $\left(\mathrm{m} / \mathrm{s}^{2}\right)$ 
ルクが必要とされている.乙れは (3)式の補正項が過 大となるためである。つまり, 動力学を考慮していな いことでこのような動作が生じてしまっている，咒長 性分解制御では加減速の切換え時でもトルクの上限は かなり抑えられている. ての加減速の切換え時には選 択する関節の組合せが変更されている. 几長性分解制 御でトルクの上限が抑えられる理由の一つはこのよう な動作の切換えにあると思われる。

Fig. 5 は比較的長い軌道をたどる場合の例である. 動作開始時にはゼロ空間ベクトル手法のほうがこ長性 分解制御よりトルクの 2 乗和が小さい．しかし軌道の 最終状態に至ると, ゼロ空間ベクトル手法ではほとん ど実行不可能なほどの大きなトルクが必要となってい る. 擬似逆行列手法では加減速の切換え時に大きな卜 ルクが必要となっている. 冗長性分解制御では両状態 ともにトルクを低く抑えている。

他の動作例を Fig. 6, Fig. 7, Fig. 8 亿示す. 乙 のなかで Fig. 6 は圥長性分解制御のほうがゼロ空間 ベクトル手法よりトルクの上限が大きい数少ない例の 一つである．筆者らはこのような任意の初期姿勢から 任意の軌道をたどるシミュレーション実験を総計 20 例行ったがその結果, 染長性分解制御が最もよくトル クの 2 乗和の最大值を抑えており, 擬似逆行列手法が それにつぎ，ゼロ空間ベクトル手法は最む悪いという 結果を得た．ただし，短い軌道運動ではゼロ空間べク トル手法が常にトルクの 2 乗和を最小化しているよう である.

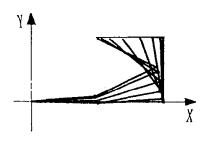

(a) Pseudo-inverse (b) Null-space matrix method

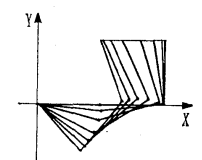
vector method

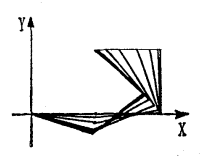

(c) Redundancy decomposition

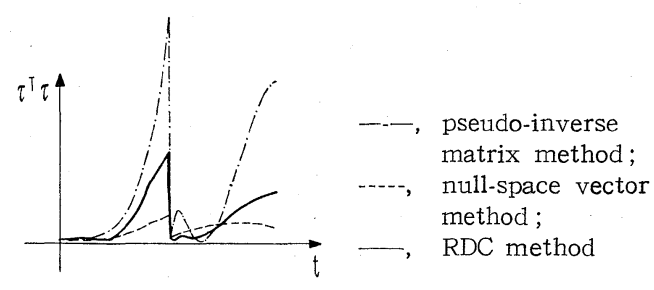

(d)

Fig. 6 The arm motion and profiles of squared torques.

Motion time $t=1.70(\mathrm{~s})$ and acceleration $a=1.0\left(\mathrm{~m} / \mathrm{s}^{2}\right)$
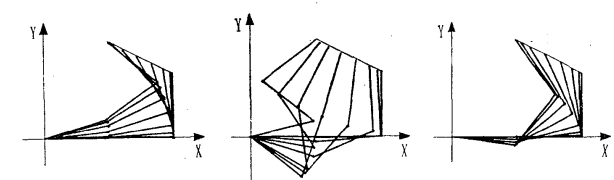

(a) Pseudo-inverse (b) Null-space

(c) Redundancy decomposition
control method

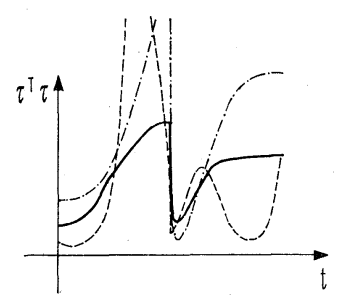

-_-, pseudo-inverse matrix method; null-space vector method;

RDC method

(d)

Fig. 7 The arm motion and profiles of squared torques.

Motion time $t=1.42(\mathrm{~s})$ and acceleration $a=2.0\left(\mathrm{~m} / \mathrm{s}^{2}\right)$
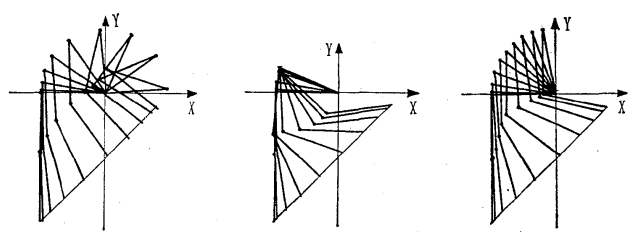

(a) Pseudo-inverse (b) Null-space (c) Redundancy matrix method vector method decomposition control method

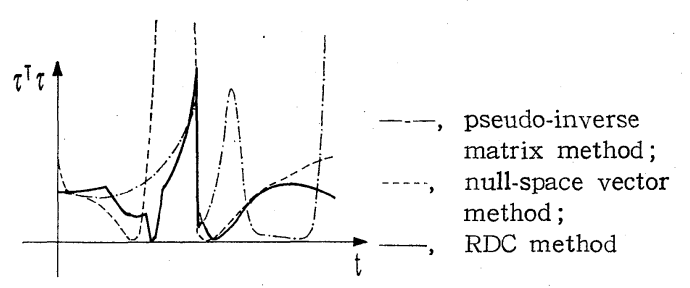

(d)

Fig. 8 The arm motion and profiles of squared torques.

Motion time $t=1.80(\mathrm{~s})$ and acceleration $a=3.0\left(\mathrm{~m} / \mathrm{s}^{2}\right)$

\section{5. 考 察}

以上のシミュレーション実験から, 提案する冗長性 分解制御は従来の手法と比較して以下の二つの大きな 特徴を有しているととが考えられる.

第一は得られる解の最適性である, ゼロ空間べクト ル手法にはトルクの 2 乗和を最小にするゼロ空間ベク トルを各瞬間ごとに選択する手法である. ゼロ空間ベ 
クトル手法がてのように最適化を図っているにもかか わらず呪長性分解制御のほうがよりトルクの 2 乗和の 最大值を抑える結果を生じていることは注目に值す る. これは以下の理由によるあのと思われる。

本論文で使用した例では，三つの関節角加速度 $\ddot{\theta}_{1}$, $\ddot{\theta}_{2}, \ddot{\theta}_{3}$ について作業平面内 2 方向 $(x y$ 方向) への加速 度の制約条件が与えられ，そのなかで評価基準を最適 化する解の誘導が時々刻々行われる．乙れらの制約条 件は $\ddot{\theta}_{1}, \ddot{\theta}_{2}, \ddot{\theta}_{3}$ の関節空間で考えるとそれぞれ一つの 平面をなす．そのためとの二つの制約条件を満足する 関節空間は Fig. 9 のように直線をなす。これを直線 $L$ 之呼ぶ. 擬似逆行列による解は原点加ら直線 $L$ への 垂線の足である点 $\mathrm{P}$ である. 罙長性分解制御による解 は $\ddot{\theta}_{1}=0, \ddot{\theta}_{2}=0, \ddot{\theta}_{3}=0$ を満足する三つの平面之直線 $L$ の交点 $R_{1}, R_{2}, R_{3}$ のいずれかである. ゼロ空間ベクト ル手法によって得られる解は，考察する時刻における マニピュレータの姿勢と運動に依存し，どの点になる かは不定である. しかし状況によっては Fig. 9 のよ うにトルクの 2 乗和の最小值が直線 $L$ 上で $\mathrm{P}$ 点が 遠

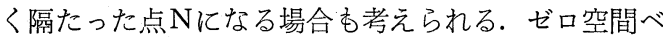
クトル手法ではこのN点の角加速度が選択される．乙 うすると，乙の時刻におけるトルクの 2 乗和は最小化 されるとしても, 角加速度は大きくなる．そのためて のような点が選択され続けると，その時刻以降関節角 速度が次第に増大し，長距離の軌道運動を行っている と過大なトルクを生成しなりればならなくなる状況が 生ずる. それに対し擬似逆行列の解である点 $\mathrm{P}$ はその 瞬間でのトルクの 2 乗和の最小化はできていないが, 角加速度は最小化されている. そのため関節角速度が 増大してゆき過大なトルクを発生しなければならない という問題は生じにくい．擬似逆行列手法では動力学 的な考察を行っていないにあかかわらず，ゼロ空間べ

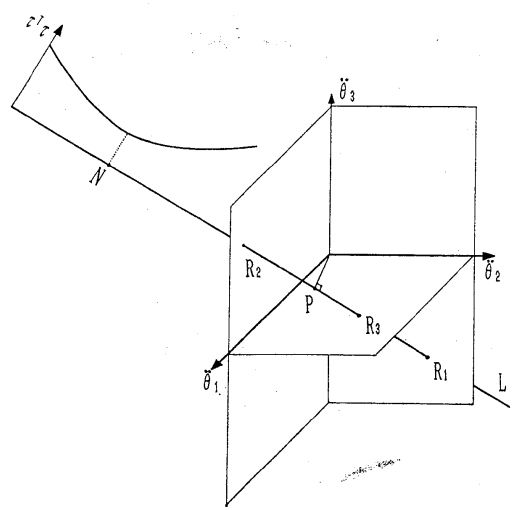

Fig. 9 The concept of joint space, constrained line $L$, and solutions
クトル手法により往々にしてより望ましい運動を生成 するととがあるという実験結果は，以上のような状況 を想定するととで理解できる.

さて，罙長性分解制御による解は点 $R_{1}, R_{2}, R_{3}$ の なかで選択するため，Fig. 9 の例では点 $\mathrm{R}_{2}$ となる. 点 $\mathrm{R}_{2}$ は擬似逆行列手法による解とゼロ空間ベクトル 手法による解の折哀的な解となっている. つまり角加 速度がそれほど大きくならない範囲でしかすトルクの 2 乗和の最小化を図った解である．そのため，乙のよ うな解を選択しながら長距離の軌道運動を行っても角 速度が増大して行ってしまうことがなく，しかもトル クの最小化すある程度計られたような動作が実現でき るあのと思われる。シミュレーションを行ったほとん どの例で，運動の開始時には攵長性分解制御のほうが ゼロ空間ベクトル手法によりそのトルクの 2 乗和が大 きいが，途中から傾向が逆転している．乙れは以上の 理由によるあのと思われる。

あち万ん圥長性分解制御む基本的には各瞬間ごとの 局所的 (local) な制御である. そのため状況によって は Fig. 6 の例のようにゼロ空間ベクトルよりあ大き なトルクの 2 乗和を発生しなければならない姿勢に追 い込まれることがある。しかし，てのような状況の発 生確率は低い。また発生したとしてもそのトルクの 2 乗和がゼロ空間ベクトル手法の場合のように発散的に 大きくなるような現象はないようである。なお，てれ らの問題をすべて解法し完全な最適解を得るには大局 的な (global) 制御 ${ }^{7), 8)}$ が必要である.

它長性分解制御の第二の特徵は実時間制御性であ る. 従来の擬似逆行列手法は特異值分解法などで擬似 逆行列を誘導する過程に，またゼロ空間ベクトル手法 ではさらにそれに慣性行列の誘導とそれを用いたゼロ 空間ベクトルの誘導に多大な演算を必要とする，大局 的な制御手法はさらにてれ以上の膨大な演算を必要と する．そのためて長度の低い場合以外は，これらの手 法は現状では実時間制御にはほとんど使用できないむ の之思われる. それに対し，穴長性分解制御で行う ${ }_{n} \mathrm{C}_{p}$ の組合せの演算は，圥長性が高くてもその中身は 高々 6 自由度についての非尣長な逆動力学演算であ る.よって, ニュートン・オイラー法などの recursive な演算を ${ }_{n} \mathrm{C}_{p}$ 個の組合せについて並列的に行うことに すれば，現状でむ十分実時間制御に利用できる．膨大 な数の並列処理演算を行う計算機システムは, 最近画 像処理関係などを中心としてかなり一般的使用され るようになってきている. しかしロボット制御の場 合, 処理すべき演算アルゴリズムを並列処理系に適す るように変更する困難さが障害となり，並列処理技術 
の特徴はまだ十分生かされていなかった，提案する冗 長性分解制御は前述したように完全に並列処理に適し たアルゴリズムである，そのため，乙の制御法を現存 の計算機システムにインプリメントするととには，ま ったく問題がないと思われる.

\section{6. あとがき}

本論文では圥長性分解制御 (RDC) と呼ぶ圥長マニ ピュレータのための新しい制御法の提案を行った. 圥 長性分解制御はまず圥長マニピュレータの自由度を 非冗長な組合せの集合に分解する．その分解された自 由度の加速度だけを時刻 $t$ から $t+\Delta t$ まで制御する あのとし, そのときの逆運動学演算, そして種々の評 価基準の演算などを非冗長なヤコビ逆行列を使用して 行う. これをすべての自由度の組合せについて並行し て行う. 得られた評価を基に最適な自由度の組合せ集 合を選択する. この選択を時々刻々繰り返すという手 順で制御を行うすのである. 几長性分解制御の有効性 は従来の擬似逆行列やゼロ空間ベクトルを使用する手 法と対比したシミュレーション実験により検討し，最 適性の高い運動が実現できること，演算を高速化でき るととなどの特徵を明らかにした，呪長性分解制御 は, 非冗長自由度数 $p$ の選択法, 評価基準の与え方 により，多様な制御法を実時間で生成する可能性を有
している. 今後てれらの多様な側面も引続き検討して いきたいと考えている.

\section{参 考 文 献}

1) J. Y.S. Luh, et al.: Resolved-Acceleration Control of Mechanical Manipulators, IEEE Trans. Automatic Control, AC-25-3, 468/474 (1980)

2) O. Khatib.: Dynamic Control of Manipulators in Operational Space, Proc. 6th IFToMM World Cong. Theory of Machines and Mechanisms, 15/20 (1983)

3) J. M. Hollerbach, et al.: Redundancy Resolution of Manipulators through Torque Optimization, IEEE Journal of Robotics and Automation, RA-3-4, 308/ 316 (1985)

4) K. Kazerounian, et al.: Redundancy Resolution of Robotic Manipulators at the Acceleration Level, Proc. 7th IFToMM World Cong. The Machines and Mechanisms, 2, 1207/1211 (1987)

5) M. Vubobratovic, et al.: A Dynamic Approach to Nominal Trajectory Synthesis for Redundant Manipulators, IEEE Trans. Systems, Man, and Cybernetics, SMC-14-4, 580/586 (1984)

6) 広瀬, 馬 : 動力学を考慮した多関節アームの最適制御, 第 5 回日本ロボット学会学術講演会予稿集, 13/14 (1987)

7) K. C. Suh, et al.: Local Versus Global Torque Optimization of Redundant Manipulators, IEEE Conf. on Robotics and Automation, CH 2413-3, 619/624 (1987)

8) Y. Nakamura, et al.: Optimal Redundancy Control of Robot Manipulator, Int. J. Robotics Research, 6-1, 32/42 (1987) 